\title{
Infodesign nas escolas como viabilizador de ambientes colaborativos
}

Infodesign in schools as a facilitator of collaborative environments

FIGUEIREDO, Luiz Fernando Gonçalves de; Doutor; Universidade Federal de Santa Catarina

Iff@cce.ufsc.br

OURIVES, Eliete Auxiliadora Assunção; Doutora; Universidade Federal de Santa Catarina

elieteourives@gmail.com

VICTORIA, Isabel Cristina Moreira; Mestranda; Universidade Federal de Santa Catarina

Isabel.mvictoria@gmail.com

FERRARI, Aldo Sigolo; Graduado; Universidade Federal de Santa Catarina

aldoferrari@uol.com.br

MACEDO, Thales Eduardo; Graduado; Universidade Federal de Santa Catarina

thales@animaking.com.br

CONTI, Paolo; Mestrando; Universidade Federal de Santa Catarina

paolo@animaking.com.br

\section{Resumo}

Visando atender as demandas de inclusão de tecnologias digitais no ensino público este artigo propõe um método em que, baseado nos mapas mentais e conceituais, o infodesign é aplicado nas escolas para viabilizar uma aprendizagem colaborativa. A proposta é benéfica tanto aos professores quanto aos alunos, que terão acesso à novas tecnologias e formas de aprendizagem. O método se baseia em princípios construtivistas, em que o conhecimento provém do resultado de um conjunto de interações constituídas pela relação recíproca do sujeito com seu meio e pelas articulações que ele está apto a produzir. A metodologia do projeto se configura como aplicada, pois trata-se de um modelo para orientação nas salas de aula e seu resultado será imediatamente aplicado na melhora do ensino.

Palavras Chave: infodesign; aprendizagem; método.

\begin{abstract}
Aiming to meet the demands of inclusion of digital technologies in public education, this article proposes a method in which, based on the mental and conceptual maps, infodesign is applied in schools to enable collaborative learning. The proposal is beneficial both to teachers and students, who will have access to new technologies and forms of learning. The method is based on constructivist principles, in which knowledge comes from the result of a set of interactions constituted by the reciprocal relationship of the subject with his environment and by the articulations that he is able to produce. The methodology of the project is configured as applied,
\end{abstract}


because it is a model for orientation in the classrooms and its result will be immediately applied in the improvement of teaching.

Keywords: infodesign; learning; method.

\section{Introdução}

A educação no Brasil necessita definir o seu papel sócio-econômico. O ensino público provedor de conhecimento e qualificação tem uma baixa capacitação frente às novas tecnologias, pois ele também tem um propósito de tirar o indivíduo da exclusão digital, pois segundo o IBGE (2013), metade dos brasileiros ainda não possuem acesso à internet.

Tentando minimizar os problemas, o artigo propõe o desenvolvimento de um projeto de infodesign nas escolas, onde será feita a integração de conteúdo de diversas disciplinas ministradas no ensino fundamental de uma escola pública através de uma rede de informações semânticas e fisicamente através de uma intranet, onde todos os alunos e professores poderão ter acesso, como forma de mediar o processo de aprendizagem. Dentro desta rede deverá ser levado em consideração os centros de interesse de cada disciplina, incluir necessidades das mesmas, observar o estilo de aprendizagem, o ritmo de adequação ao sistema, a motivação dos alunos, etc.

Como resultado do método ele deve causar grande impacto, sendo um recurso para resgatar alunos que perderam o interesse escolar e aumentar a motivação dos alunos tornando as aulas mais dinâmicas, além de estar contribuindo para a exclusão digital.

É notável a dificuldade em lidar com informação que se apresentam numerosas e com alto grau de complexidade. A informação assim tornar-se o objeto principal a ser trabalhado, ela assume papéis de matéria-prima e produto, dentro de uma filosofia de entradas e saídas, num processo contínuo de elaboração.

Para que alunos e professores de escolas públicas possam desfrutar desta nova forma de ensino e aprendizagem, este trabalho propõe um projeto que poderia tornar a vida escolar muito mais atraente, além de ser um agente facilitador para que as disciplinas sejam melhores compreendidas pelos alunos, através desta nova tecnologia.

O aprendizado deverá ser um processo, com jornada, dando ênfase no "aprender a aprender" tendo como base desafio e motivação. Os alunos deverão ser estimulados a seguir áreas de interesse específico (SILVEIRA, 2001).

A pesquisa, ora proposta, teve como premissa que as escolas de ensino fundamental voltem a estreitar o elo entre alunos e professores com a tecnologia, através de uma rede de informações elaborada através do infodesign (arquitetura e design da informação).

Este projeto tem como objetivo propor às escolas o uso do infodesign para dar forma a organização das informações, estruturadas a partir dos mapas mentais/conceituais, visando atender uma nova lógica de organização dos conteúdos, compatíveis ao funcionamento do cérebro humano.

Esta técnica tem como objetivo relembrar tudo aquilo que a nossa mente pensa, a respeito da informação com base na ideia central.

Como procedimentos metodológicos foi estipulado a estruturação dos conteúdos programáticos aos moldes dos mapas mentais/conceituais para mostrar a horizontalidade e 
verticalidade dos conteúdos de forma integrativa e associativa.

\section{Design de informação}

Segundo o Instituto Internacional de Design da Informação (2014) e Erlhooff \& Marshall (2008) o design de informação atua sobre a configuração da informação. É uma área do design gráfico que objetiva equacionar os aspectos sintáticos, semânticos e pragmáticos que envolvem os sistemas de informação através da contextualização, planejamento, produção, construção e definição de interface gráfica da informação junto ao seu público alvo. Seu princípio básico é o de otimizar o processo de aquisição da informação efetivado nos sistemas de comunicação analógicos e digitais.

Designers necessitam apresentar as informações de forma eficaz e eficiente para o público alvo no tempo correto. Essa habilidade deve ser desenvolvida para que o profissional possa explicar, orientar e ensinar de forma a potencializar o conhecimento (Horn, 1999).

\section{Infodesign}

De acordo com Gui Bonsiepe (2001), o trabalho envolve o design na contribuição de estruturar, organizar e tornar acessíveis conjuntos de informações. O objetivo final é facilitar o reconhecimento e a compreensão de fatos mediante a seleção, organização, hierarquização e combinação de distinções visuais possibilitando uma ação efetiva. É mais do que tradução ou transformação visual. O trabalho do infodesigner começa mais cedo, com a estruturação de dados, sendo assim exerce também uma função autoral.

\section{Arquitetura da informação}

Na ciência da computação e tecnologia informacional, o termo design de informação é muitas vezes usado como sinônimo para (mas não é necessariamente a mesma disciplina que) arquitetura de informação, o design de sistemas de informação, bancos de dados, ou estruturas de informação.

Pode-se definir Arquitetura de Informação como o design estrutural de grupos de informações relacionadas ou, a arte e ciência de organizar e rotular Web sites, Intranets, comunidades online e software para dar suporte à usabilidade e facilidade de obtenção de informações, e também, como uma comunidade emergente de profissionais focada em trazer princípios de design e arquitetura para o ambiente digital.

Estas definições não são definitivas e exprimem apenas parte das atribuições de um Arquiteto da Informação.

Esse é um campo de trabalho que ainda está se estruturando, alguns princípios fundamentais já são estruturados, porém os limites ainda são muito amplos. Esta falta de limitações desafia os profissionais a refletir continuamente sobre a responsabilidade de procurar novas soluções.

É a criação de um sistema consistente e funcional, que permita o usuário saber: onde está, para onde ir e o que fazer.

O objetivo é a organização de grandes massas de dados, preparando rotas de acesso a eles. Isso inclui: tornar o acesso a informação indesejada mais difícil, sendo assim o acesso a informação desejada mais fácil, também definir o espaço de informação em níveis de interesse e eliminar o 
ruído das informações.

Ao Arquiteto de Informação é dado o papel de construir os caminhos da informação, suas conexões e desdobramentos, a fim de contribuir para a divulgação do conhecimento

Especificar o funcionamento do sistema tais como:

- definição de fluxos;

- posicionamento de elementos funcionais ;

- definição de nomenclatura das seções;

- definição de tecnologias;

- estruturação do conteúdo em seções e sub-seções.

A Organização da informação sob a luz do arquiteto visa uma hierarquia conforme descrito na figura 1. As 3 dimensões da Arquitetura da Informação esta descrita na figura 2.

Figura 1 - Hierarquia para organização

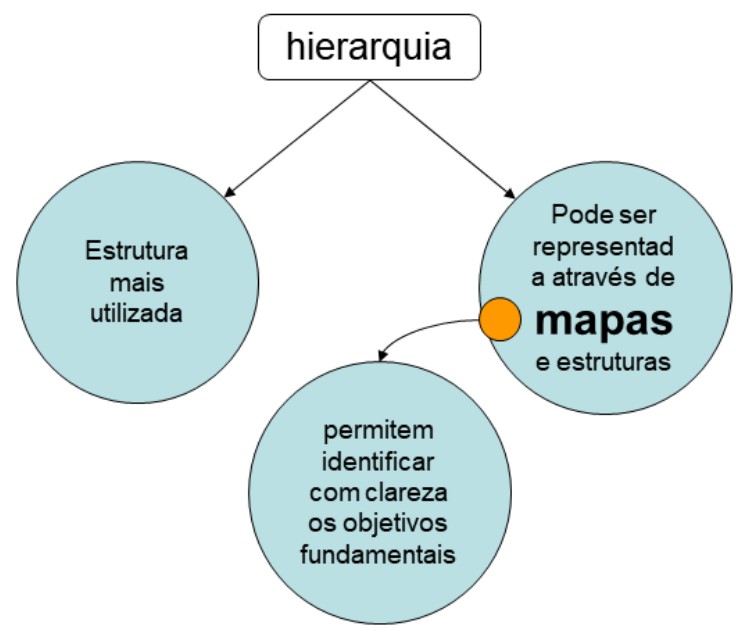

Fonte: Elaborada pelos autores

Figura 2 - As 3 dimensões da Arquitetura da Informação 


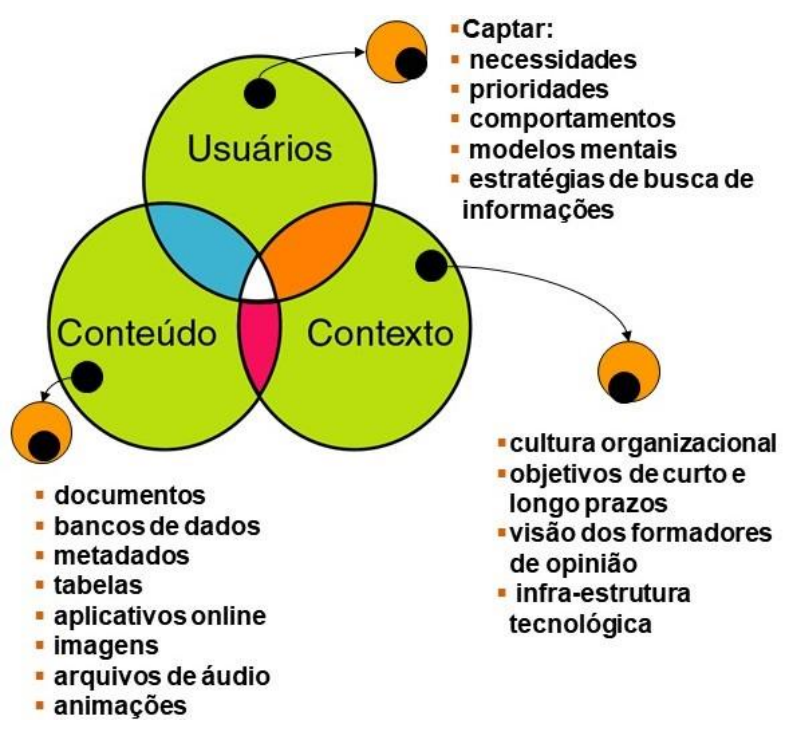

Fonte: Elaborada pelos autores

\section{Informação}

Para McGarry (1999, p.3), o conhecimento é um 'case' sinônimo do termo informação. A etimologia do vocábulo diz que: "Informação tornou-se popular logo após a invenção da imprensa no século XV, quando o normal era lançar mão de uma palavra em latim par expressar uma nova idéia. A raiz do termo vem de formato e forma, ambos transmitem a ideia de moldar algo ou formar um "molde". Era também a palavra latina para o que chamaríamos de notícia".

Figura 3 - Definição de informação

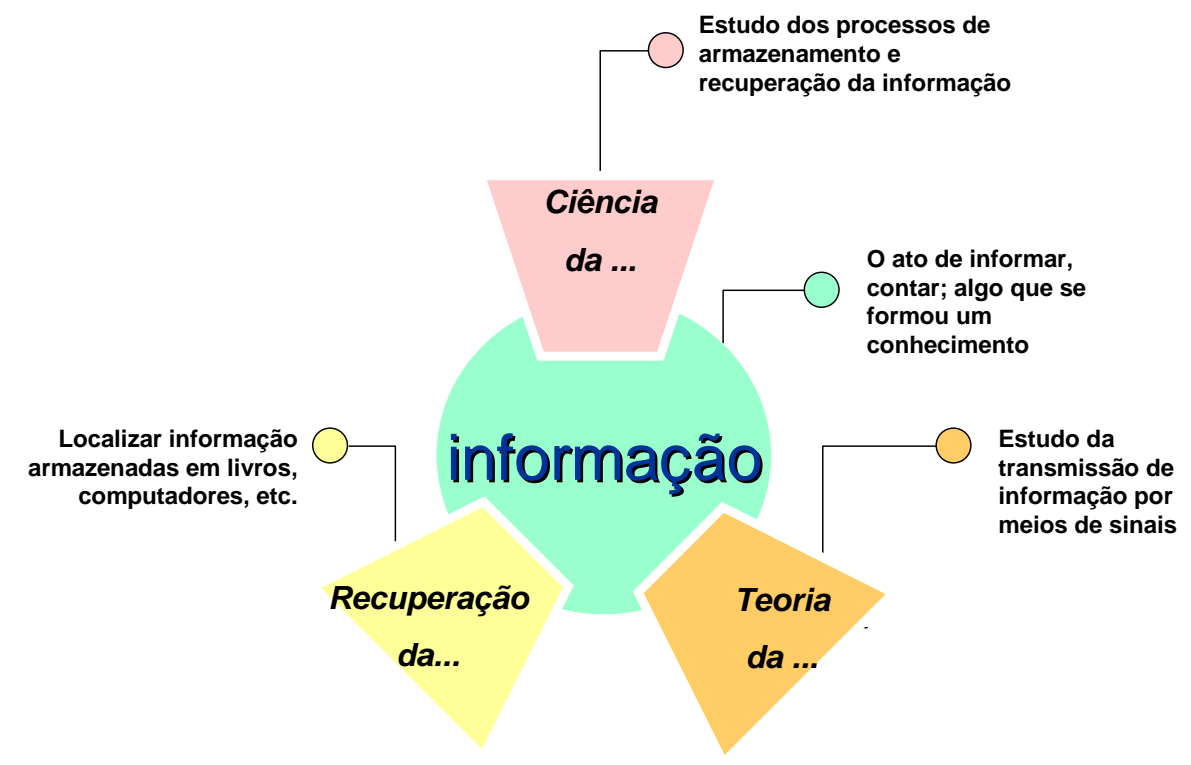

Fonte: Adaptado de Oxford dictionary of current english

Norbert Wiener (1960) especialista no assunto e fundador da cibernética, no seu estudo da comunicação e controle em seres humanos e máquinas, dá a sua definição de informação: 
Informação é o termo que designa o conteúdo daquilo que permutamos com o mundo exterior ao ajustar-nos a ele, e que faz com ajustamento seja nele percebido. Viver de fato é viver com informação.

Algumas outras definições citadas por McGarry (1999), demonstram a influência recebida da doutrina da teoria da informação, ou teoria da comunicação:

\begin{abstract}
Informação é algo de que necessitamos quando nos deparamos com uma escolha. Qualquer que seja seu conteúdo a quantidade de informação necessária depende da complexidade da escolha. Se depararmos com um grande espectro de escolhas igualmente prováveis, se qualquer coisa pode acontecer, precisamos de mais informação do que se encarássemos uma simples escolha entre alternativas.

O que acrescenta algo a uma representação [...] Recebemos informação quando o que conhecemos se modifica. Informação é aquilo que logicamente justifica alteração ou reforço de uma representação ou estado de coisas. As representações podem ser explícitas como um mapa ou proposição, ou implícitas como no estado de atividade orientada para um objetivo do receptor.

Informação refere-se não tanto ao que você diz, mas ao que poderia dizer, ou seja, informação é a medida da liberdade de escolha quando se seleciona uma mensagem.
\end{abstract}

O que é passível de discernimento, diante das definições acima, é uma variação interessante dos atributos da informação, tais como:

- Considerada como quase-sinônimo do termo fato;

- Um reforço do que se conhece;

- A liberdade de escolha ao selecionar uma mensagem;

- A matéria-prima da qual se extrai o conhecimento;

- Aquilo que é permutado com o mundo exterior e não apenas recebido passivamente;

- Definida em termos de seus efeitos no receptor;

- Algo que reduz a incerteza em determinada situação.

Segundo McGarry (1999), especialistas e cientistas da informação frequentemente empregam o termo para designar qualquer assunto contido num texto ou documento.

\title{
6 A organização e estruturação da informação
}

Para a organização e estruturação da informação, o que é marcante, principalmente nas diferentes definições, é o emprego metafórico de mapas e estruturas. A metáfora, junto com sua parenta próxima, a analogia, constitui parte importante dos modos como solucionamos problemas e pensamos a respeito do mundo. É a maneira como explicamos as coisas para nós mesmos e para os outros, sempre comparando objetos que se parecem, mas não são literalmente idênticos. Daí a ideia de informação como algo que altera a natureza ou relações dentro de um mapa. Não há, aqui, uma forte insistência na existência de um mapa (literalmente) dentro das cabeças das pessoas. Os psicólogos dizem que cada pessoa possui um mapa cognitivo que se modifica à medida que aprende. Em suma, são traçados mapas de padrões das experiências de cada um conforme um modelo interno do mundo exterior. Esses mapas são utilizados para organizar a vida - e procurar informação. Cada vez que este mapa é alterado, houve aprendizado, o que indica 
uma relação próxima entre informação, assimilação e aprendizagem.

\subsection{As ferramentas de estruturação: mapas mentais, mapas conceituais e cognitivos}

Esta seção é a parte fundamental para a construção do modelo, pois, mostra as ferramentas utilizadas para estruturar a problemática definida anteriormente.

Essas ferramentas são as geralmente usadas em modelos decisórios, como por exemplo: mapas, mentais; conceituais e cognitivos; estrutura arborescente com critérios pré-definidos, que possam permitir ao tomador de decisão de uma empresa ou outros atores interessados, avaliar as ações potenciais e expressarem os seus juízos de valor sobre a problemática em questão.

Geralmente, as pessoas que trabalham com o processo decisório, recomendam que se efetue uma lista de objetivos, mas, não explicam quais são os objetivos que deveriam ser listados. O questionamento está em como fazer para listá-los. Ou como usá-los? Porém, apenas listar esses objetivos, não é suficiente, é uma análise muito superficial. O que necessita de ferramentas mais apropriadas, como os mapas citados anteriormente, que, de maneira simples e organizada mostra a importância dos objetivos, informações, facilitando o processo de decisão.

O mapa mental proposto por Buzan (2005), permite organizar informações de muitas fontes em uma ordem lógica utilizando o mínimo possível de palavras (uma ou no máximo duas palavras para cada tópico) e exagerando-se nos recursos visuais. Este tipo de mapa pode ser usado para muitas coisas, desde uma simples anotação até sessões de brainstorming e preparação de um projeto de pesquisa, melhorando naturalmente a habilidade de pensar numa forma sistemática, e assim aumentando a eficiência da atividade do cérebro, naturalmente.

O mapa conceitual foi desenvolvido pelo pesquisador norte-americano Joseph Novak. Novak é considerado o criador dos Mapas Conceituais, porém a sua teoria original foi baseada na teoria da aprendizagem significativa desenvolvida por David Ausubel. Ausubel desenvolveu-a na década de 60 e 70, e no final da década de 70, Novak adaptou-a e contribuiu com a teoria da aprendizagem significativa, modificando o seu foco do ensino do modelo estímulo -> resposta -> reforço positivo para o modelo aprendizagem significativa $\rightarrow$ mudança conceitual $\rightarrow$ construtivismo.

Dessa forma, a abordagem do mapa conceitual se baseia em uma teoria construtivista, no qual o indivíduo constrói o seu conhecimento e significado a partir da sua predisposição para realizar esta construção. Servem como instrumentos para facilitar o aprendizado do conteúdo sistematizado em conteúdo significativo para o aprendiz. O mapa conceitual proposto é a elaboração de uma lista que descreve a relação das ideias do pensamento pré-adquiridas ao longo de um processo de aprendizagem na construção de conhecimentos e vai-se arquivando na memória.

Ensslin et al (2001), recomendam identificar, estruturar, analisar e entender esses objetivos através da construção de um mapa cognitivo. O mapa cognitivo é uma hierarquia de conceitos relacionados por ligações meios e fins. Este tipo de mapa permite que os atores envolvidos revelem os aspectos que considerem relevantes a serem considerados no problema através de conceitos superiores na hierarquia e forneçam uma série de ações visando atingir os objetivos estratégicos almejados por eles, através de conceitos subordinados na hierarquia.

\subsubsection{A construção dos mapas mentais}


Basicamente para se criar um Mapa de Aprendizagem deve-se levar em consideração as seguintes observações:

- O tema principal fica no centro (em um círculo);

- Deste centro você irá ligar ramificações com outros itens através do uso de palavras chave, que estejam diretamente ligados a este tema principal;

- Destas ramificações, poderão surgir novas e novas ramificações na medida em que forem necessárias;

- Para cada item (ou para os mais significativos, crie desenhos para simbolizá-los);

- Fazer uso de softwares livres específicos criar mapas mentais.

A definição de um mapa é uma imagem de uma ideia com um tópico no centro que se ramifica através de outros tópicos relacionados (Figura 4).

Figura 4 - Exemplo de mapa mental

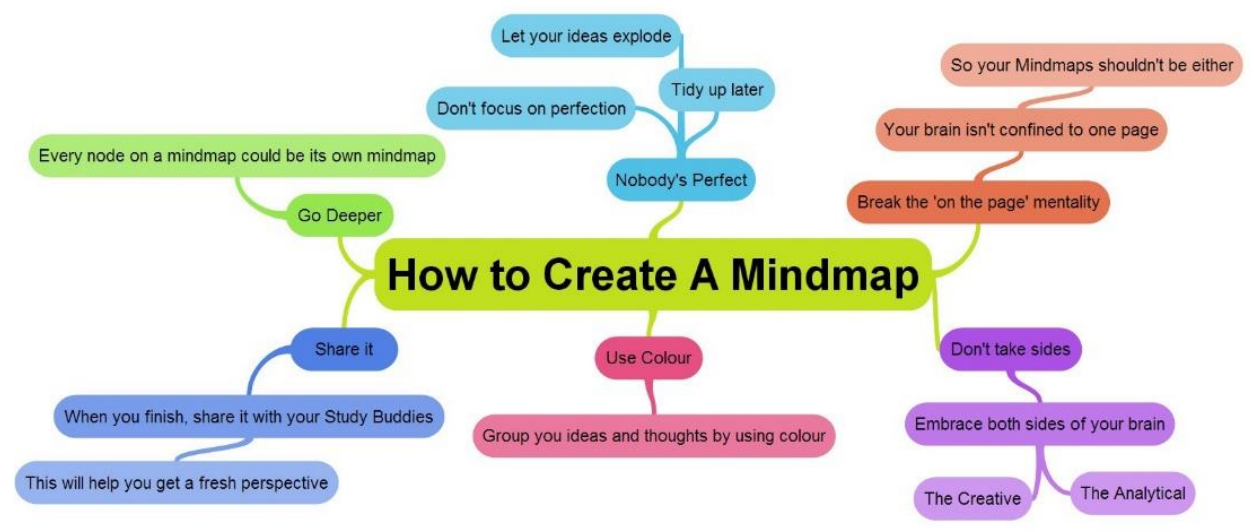

Fonte: Examtime

Um mapa radial, a definição de radial aqui é uma rede circular de aranha - enquanto as imagens emanam de um tópico no centro. Quanto mais longe do centro o mapa continua, quanto mais detalhado o mapa será. Pode-se escolher uma das próximas duas direções para organizar ramificações em um mapa radial. De um mais alto ponto do mapa para um ponto abaixo é o padrão mais básico (Figura 5).

Figura 5 - Mapa mental radical: explicação 


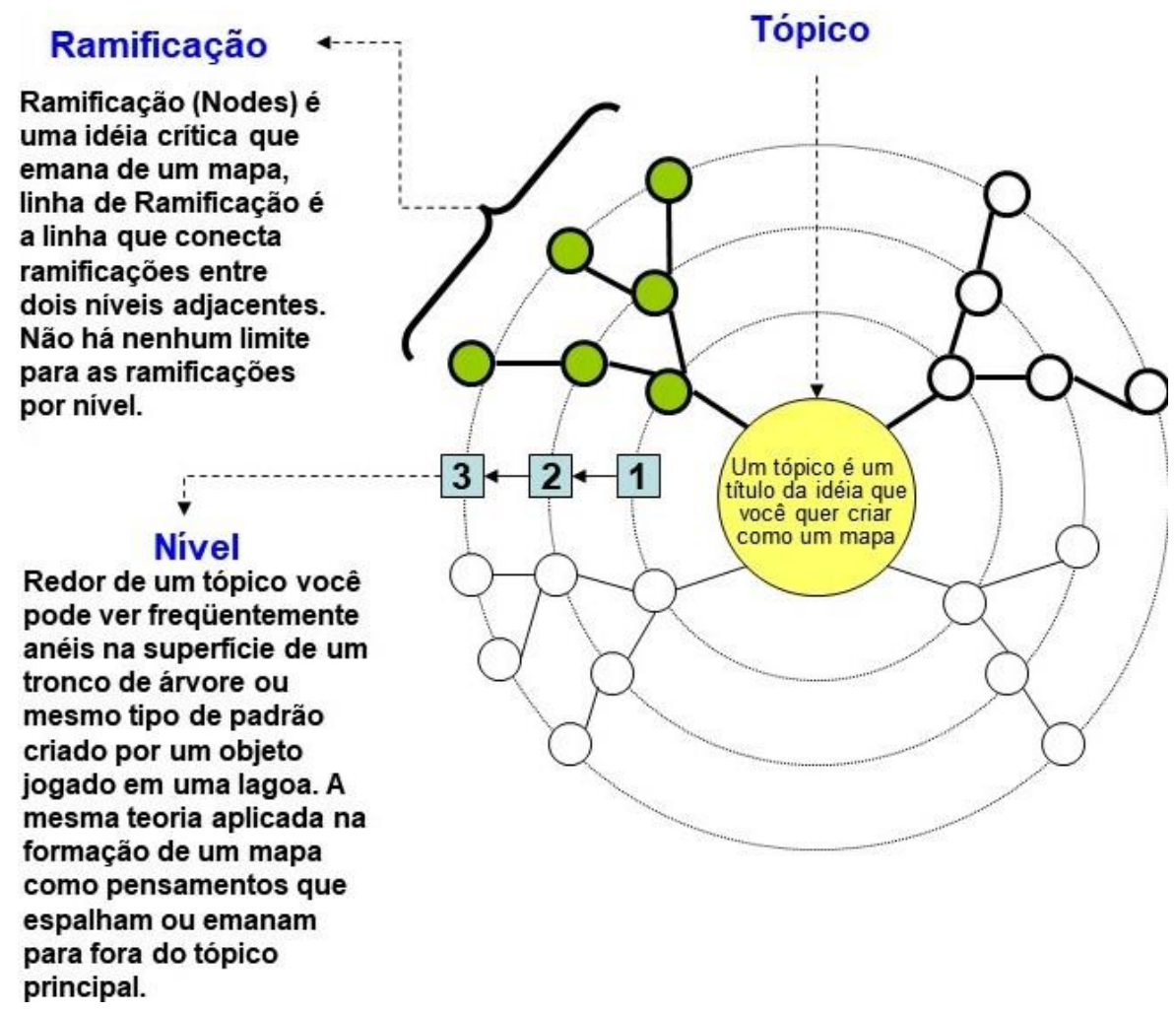

Fonte: Elaborado pelos autores

\section{Método projetado proposto}

A pesquisa, ora proposta, tem como premissa que as escolas de ensino fundamental voltem a estreitar o elo entre alunos e professores com a tecnologia, através de uma rede de informações elaborada através do INFODESIGN como mostra a estrutura geral (Figura 6).

Figura 6 - Como o INFODESIGN pode interferir no processo de construção da informação. 


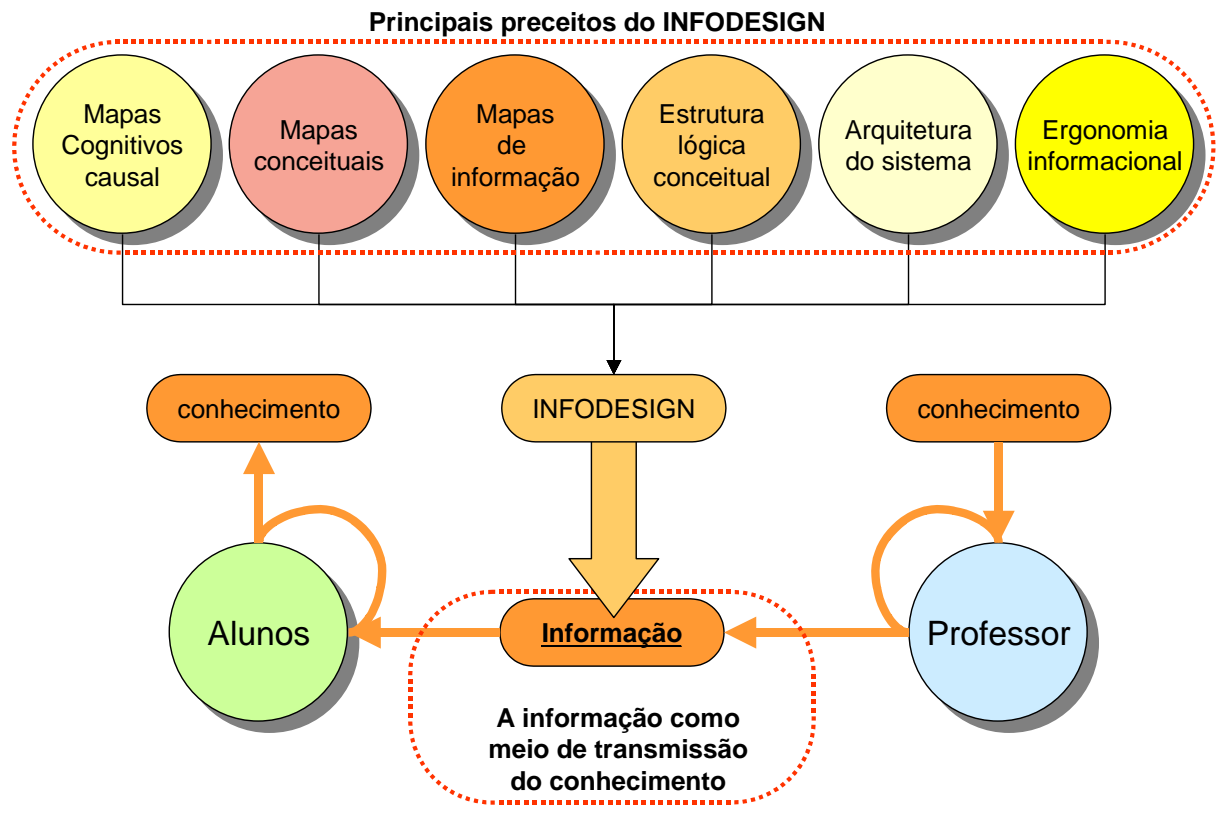

Fonte: Elaborado pelos autores

A metodologia de desenvolvimento deste trabalho pode ser classificada como pesquisa aplicada, pois trata-se de um modelo para orientação nas salas de aula e seu resultado será imediatamente aplicado na melhora do ensino, no caso naqueles referentes as disciplinas de um curso de ensino fundamental (LACATOS, 1996).

Para construção do conteúdo serão coletados todos os dados necessários de cada disciplina tais como: Português, Matemática, Ciências, Estudos Sociais com os respectivos professores. Este dados serão coletados de forma colaborativa através de técnicas de mapeamento cognitivo (ENSSLIN, 2001), mapa conceitual (BORBA, 1999) e mapas de informação, que poderão ser retroalimentados quando for necessário (figura 7). Uma vez com os dados e o usuário reconhecidos, serão modeladas estas informações para um melhor aproveitamento e formando mapas de informação.

Figura 7 - Reestruturação do método de trabalho 


\section{Construção da rede informação semântica}

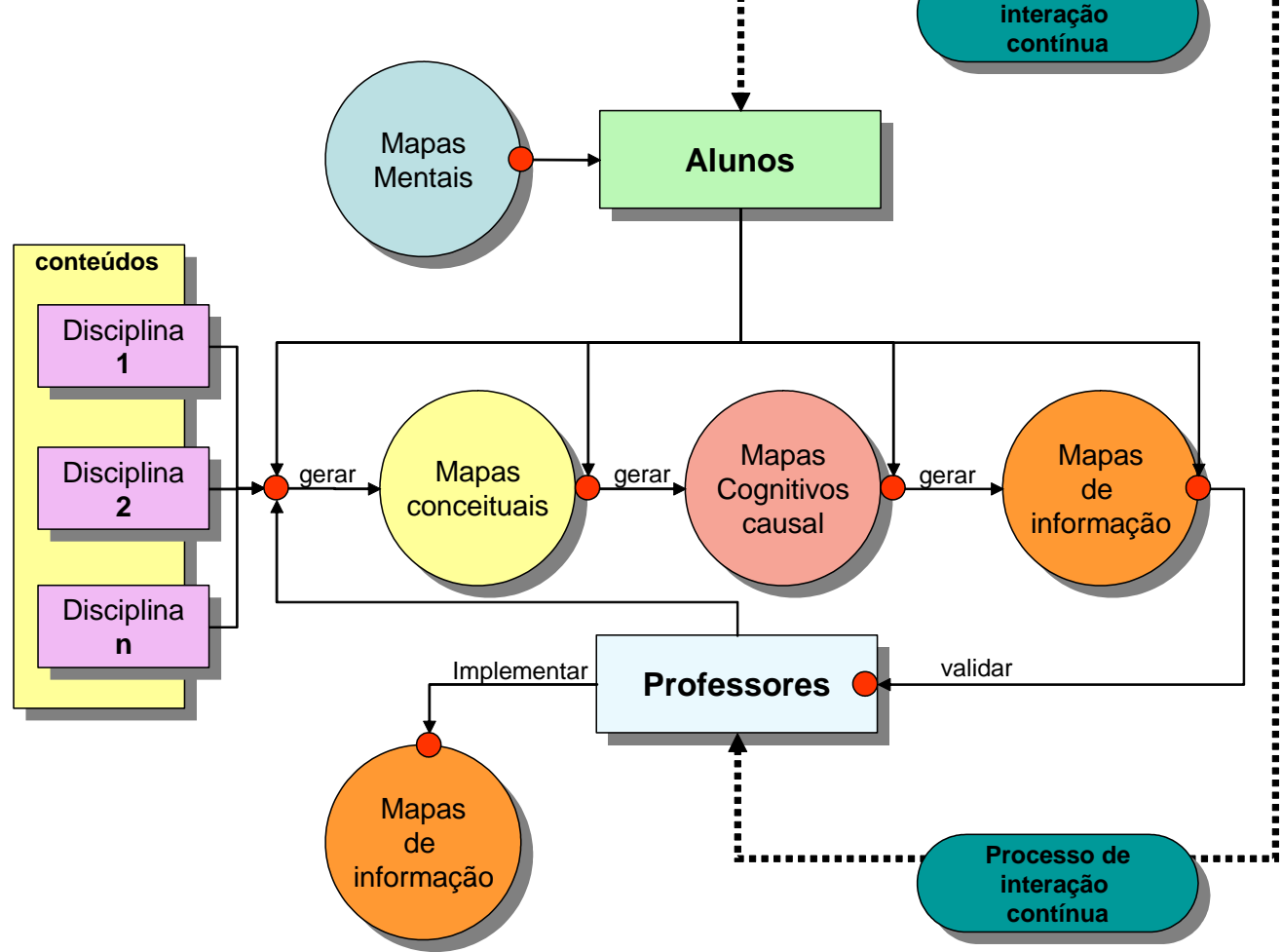

Fonte: Elaborada pelos autores

Será utilizado hipertexto, um tipo de texto que permite o uso de ligações (links) para outros documentos ou para partes do mesmo documento. $E$ também será criado um banco de informações onde estarão divididos de maneira estrutura as informações das disciplinas.

É gerado conteúdo estruturado com os mapas mentais, conceituais e cognitivos, utilizando uma construção lógica com o design da informação e, então, é disponibilizado o portal Infodesign (figura 8).

Figura 8 - Atividades projetadas 


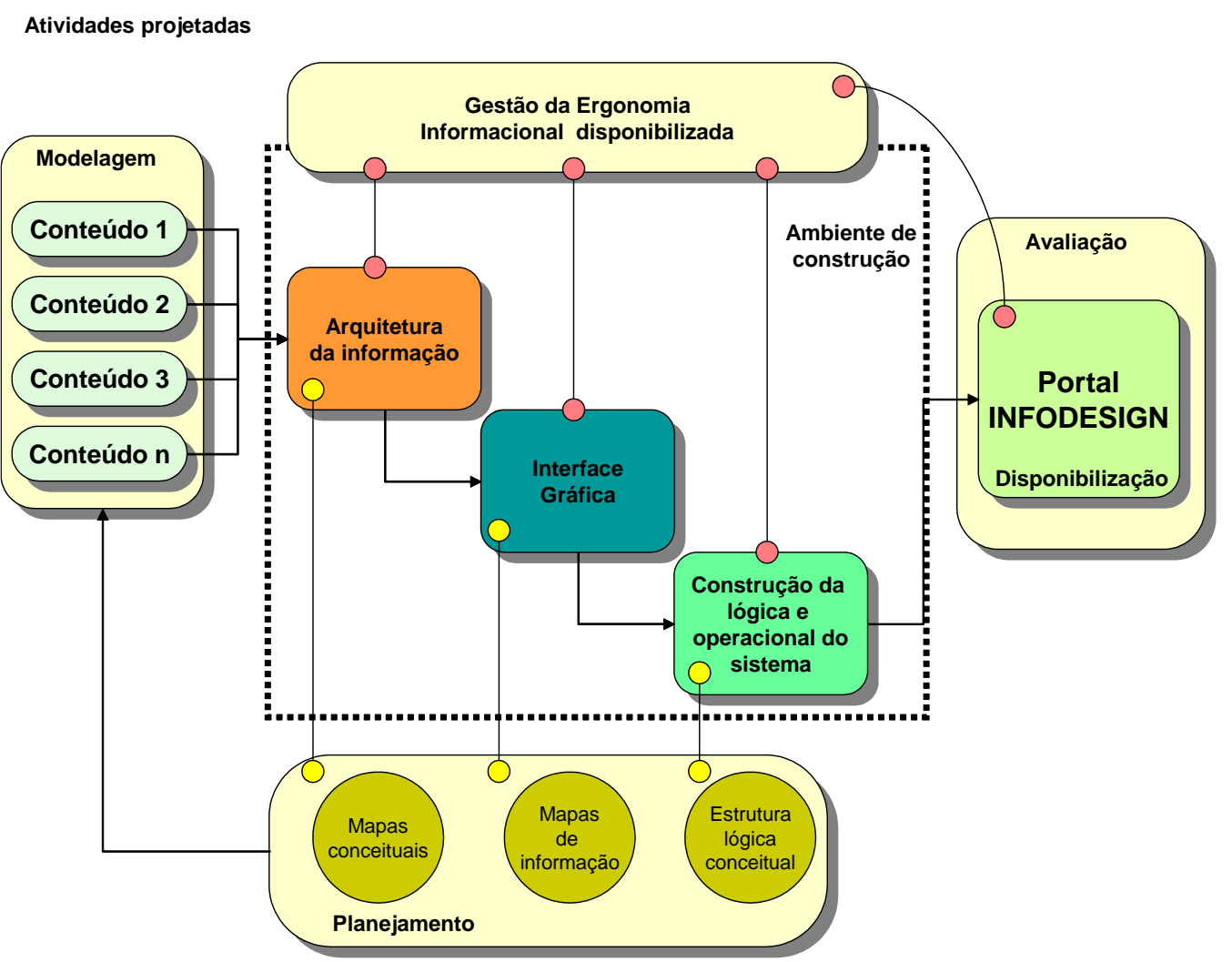

Fonte: Elaborada pelos autores

Implementar o projeto INFODESIGN NA ESCOLA como viabilizador de ambientes colaborativos, levando as tecnologias contemporâneas para ambientes escolares públicos. Assim a sala de aula com a intranet transforma-se num ambiente interativo em que a aprendizagem cooperativa passa ser maior. Além de dar suporte para qualificação do professor, deixando o receio das novas tecnologias sobrepor o interesse do conhecer (figura 9).

Figura 9 - metodologia e estratégia geral para utilizar no projeto INFODESIGN NA ESCOLA

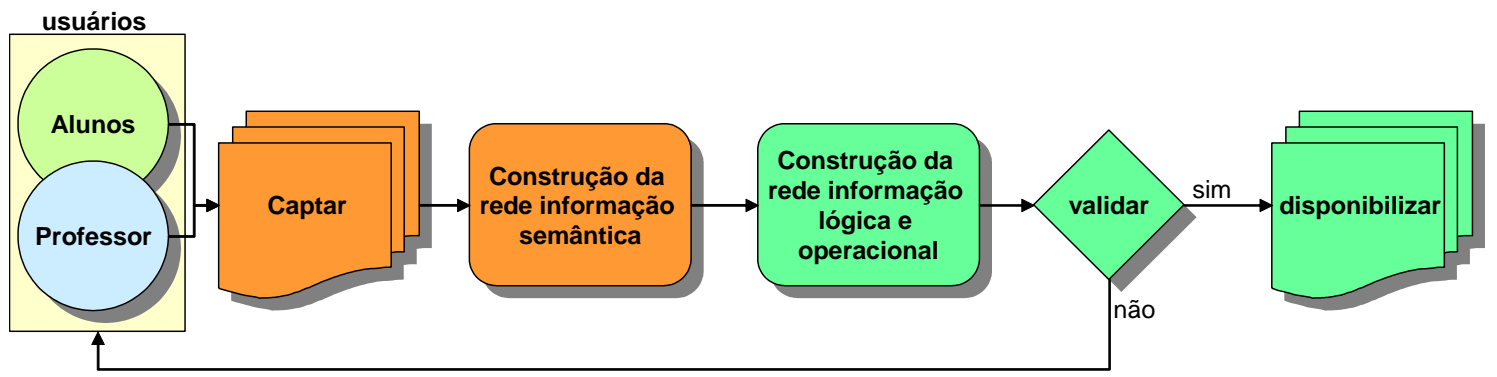

Fonte: Elaborada pelos autores

O professor passa a ser o mediador de toda esta informação. Criando pequenos grupos de pesquisa dentro da sala de aula, fornecendo a direção, a orientação e a inspiração para os alunos utilizarem melhor os recursos criados pelo projeto. Além disso, o professor também cria um perfil de aluno ao se ver envolvido com uma nova tecnologia e aprendendo os novos caminhos de funcionamento do INFODESIGN. 


\section{Conclusão}

A partir da estruturação desta metodologia de integração, de retorno da percepção do aluno somado a utilização dos mapas conceituais que proporcionou uma visão macro dos principais conteúdos dado em aula, foi possível gerar ações para o ensino do desenho técnico com o uso de diferentes instrumentos e proporcionar o conhecimento ao aluno, principalmente aqueles que possuem carga horária e conteúdo programático reduzido.

A ideia deste trabalho está embasada nos princípios construtivistas, que partem dos pressupostos de que os conhecimentos não provem tão somente da programação inata do sujeito (usuário) e tampouco da sua única experiência sobre o objeto, mas do resultado de um conjunto de interações constituídas pela relação recíproca do sujeito com seu meio e pelas articulações que ele está apto a produzir. Tais interações promovem construções cognitivas sucessivas, capazes de produzir novas estruturas em um processo contínuo e incessante.

Conforme ficou demonstrado nos capítulos precedentes, organizar, arquitetar e dispor a informação em um ambiente é uma tarefa das mais complexas porque, além de envolver um grupo de profissionais, requer também, conhecer previamente o perfil do usuário e isto demanda, muitas vezes, a integração de técnicas peculiares à ciência da cognição e da computação.

A ciência da cognição aborda o indivíduo em si, presente na obtenção e armazenamento dos dados, na elaboração da informação, (como autor/mediador) e também no consumo final da informação (usuário final).

A informação, por sua vez, é resultado do processamento dos dados já obtidos do mundo real, pelos indivíduos (autores/mediador) envolvidos nessa tarefa no contexto do domínio do problema.

O enfoque cognitivo pretendido neste trabalho confirma-se como meio para a obtenção de estruturas de informações adequadas aos usuários finais, principalmente quando evidencia representações individuais diferenciadas para um mesmo tipo de contexto, a partir de um grupo de pessoas pertencentes ao mesmo grupo social.

Diante do exposto, configuram-se as contribuições deste trabalho às áreas da ergonomia informacional, arquitetura de informação, ecologia da informação, sistema de informação e infodesign, disponibilizando aos profissionais que atuam nesses segmentos um instrumento eficaz na captação e análise de estruturas de informações, podendo ter sua aplicabilidade estendida à avaliação de ambientes de informação (mídias analógicas e digitais), bem como ao entendimento dos conflitos gerados em sua utilização.

Tal constatação permite afirmar que é possível, a partir de pesquisas individuais, identificar diversos pontos em comum, no que se refere ao uso da estruturação (desenho) da informação com as técnicas de mapa cognitivo e análise orientadas a objetos. Assim caracterizada, a pesquisa individual é defendida porque a estrutura da informação é única para cada indivíduo, e a ciência da informação, busca um desenho apoiado nas semelhanças identificadas nas múltiplas estruturas individuais.

Os mapas cognitivos revelam a percepção inconsciente do usuário e o que este espera de um ambiente informacional adaptado para atender às suas necessidades de realização, através da expressão gráfica. Os mapas cognitivos podem auxiliar no processo de entendimento daquilo que 
os usuários desejam realmente de seu ambiente, principalmente quando se trata de informação de interesse social (educação, política, saúde).

Segundo as fontes pesquisadas e segundo o uso continuo dessas técnicas, os mapas cognitivos, como uma ferramenta consagrada na resolução de problemas complexos, revelam através da verbalização estruturada, as ações e percepções do usuário. A conjugação das duas ferramentas (mapa cognitivo e análise orientada à objetos) se mostra eficiente, na representação mental do usuário porque abstrai seus desejos, sentimentos e interesses em relação às informações que se deseja realmente veicular.

\section{Referências}

BONSIEPE, Gui. Design, cultura e sociedade. São Paulo: Blucher, 2001.

BUZAN, T. Mapas Mentais e sua Elaboração. São Paulo: Cultrix, 2005,118p.

CRUZ, A. X.; SILVA, M. A. R.; Inclusão Digital: A inserção das tecnologias informacionais nas escolas públicas da RMN e PROINFO em Natal/RN. Rio Grande: Pluscom, 2013, 170p.

ENSSLIN, L material de aula. Laboratório MCDA, Depto. de Engenharia de Produção, Universidade de Santa Catarina, 1998.

ENSSLIN, L.; MONTIBELLER NETO, G.; NORONHA, M. S. Apoio a Decisão: Avaliação Multicritério de alternativas. Florianópolis: Insular, 2001, 296 p.

ENSSLIN, S.R. Simplificação no Processo Decisório de Problemas Multicritérios Complexos. Florianópolis - Brasil, 1995. Dissertação de Mestrado. Depto. de Engenharia de Produção, Universidade de Santa Catarina.

ENSSLIN,L.; MONTIBELLER, N G.; NORONHA, S. M. Apoio à Decisão: Metodologia para Estruturação de Problemas e Avaliação de Alternativas. Insular:Florianópolis, 2001, 296p.

ERLHOOFF, M; MARSHALL, M. Design Dictionary: Perspectives on Design Terminology. Basel, Boston, Berlin: Birkhäuser, 2008.

HORN, R. Information design: emergence of a new profession. In: Jacobson, R. (Ed.) Information Design. Cambridge, Mass: MIT Press, 15-33, 1999.

IIID - International Institute of Information Design. Core Competencies, What information designers know and can do Disponível em www.iiid.net/PDFs/ idxPublication.pdf Acesso em: 28 mar. 2018

LASTRES, A. L. M. A globalização e o papel das políticas de desenvolvimento industrial e tecnológico. Texto para discusão n. 519. Brasília: IPEA, 1997.

LASTRES, A. L. M. Globalização, informação e conhecimento na nova ordem mundial. Informare, vol. 3, n.1-2, Rio de Janeiro: PPCI/IBICT. 1997

LASTRES, A. L. M., Sarita Albagli (organizadoras). Informação Globalização na era do conhecimento. Rio de Janeiro: Campus, 1999.

LAUDON, Kenneth C.; LAUDON, Jane P. Management information systems: new approaches to organization \& technology. 5 th ed. New Jersey: Prentice Hall, 1998.

McGarry, Kevin. O contexto dinâmico da informação: uma análise introdutória; tradução de 
Helena Vilar de Lemos. Brasília, DF: Briquet de Lemos/Livros, 1999.

MILLER, George. The psychology of communication. Harmondsworth: Peguin Books, 1966, p.8.

Novak, J.D. e Gowin, D.B. Aprender a aprender. 1a ed. em português. Lisboa: Plátano Edições Técnicas, 1984, 212p.

THOMPSON, John. A mídia e a modernidade: uma teoria social da mídia. 3 ed. Petrópolis: Vozes, 1998.

UNESCO/UNEP/IEEP. Environmental Education: Module for Pre-service Training of science Teachers and Supervisiors for Secundary Schoois. New York, v.7. 1983. 224p.

WINNER, Nobert. The human use of human beings: cybernetics and society. Cambridge, Mass. 